\title{
Influence of Curing-Form Material on the Chloride Penetration of Off- Shore Concrete
}

\author{
Sangjun Park ${ }^{1) *}$, and Yeol Choi ${ }^{2)}$ \\ (Received August 7, 2012, Accepted November 22, 2012, Published online December 18, 2012)
}

\begin{abstract}
This paper presents an experimental study on the pore and penetration of chloride in seashore concrete depending on types of curing forms. Three types of concretes (Plain concrete, MSF concrete and FA concrete) with four different form types (wood, coating wood, steel and polypropylene film) were examined. The test results show that the air volume in concrete was relatively higher with steel and polypropylene forms than others, and wood form shows the least air volume. The penetration of chloride depending on type of form is showed a wide variability, that is, the values on plain concrete, MSF concrete and FA concrete are 115.2, 125.5 and $121.6 \%$, respectively. Based on the present study, concrete should be considered the conditions of curing form-type for durable concrete.
\end{abstract}

Keywords: duracrete, chloride ingress time, form facing material, interfacial transition zone.

\section{Introduction}

A concrete should be prepared by mix proportions, construction methods and assessment tools of targeted concrete structures. Specially, a seashore concrete is prepared to have enough resistance against the penetration of chloride ion because the chloride concentration of concrete results in corrosion of reinforced steel. The evaluation of resistance to chloride ion penetration recommended by NT Build 492 (The Rapid Chloride Migration Test) (Nordtest Method NT Build 492 1999) is "Electrical Indication of Concretes Ability to Resist Chloride Ion Penetration” which can estimates the durability of concrete structures using the level of resistance to chloride ion penetration. However, consideration of the curing-form material is an important factor in evaluation of resistance to chloride ion penetration, because the chloride ion migrates into the form primarily. The Barnes model (Barnes et al. 1978) shown in Fig. 1 supported this consideration due to the $40 \mu \mathrm{m}$ of interfacial transition zone between form and concrete.

Rukzon and Chindaprasirt (2011) investigated the resistance to chloride penetration of concrete containing fly ash of various finenesses. Three different fly ash finenesses viz.,

\footnotetext{
${ }^{1)}$ Architectural Engineering Research Team, DAEWOO E\&C, Suwon 440-800, Korea.

*Corresponding Author; E-mail: concrete@daewooenc.com

${ }^{2)}$ School of Architecture and Civil Engineering, Kyungpook National University, Daegu 702-701, Korea.

Copyright ( $\odot$ The Author(s) 2012. This article is published with open access at Springerlink.com
}

original fly ash, $45 \%$ fine portion $10 \%$ fine portion fly ashes were used for the study. Chloride resistance of concrete was evaluated using the measurement of the Coulomb charge as per ASTM C1202 and by determination of chloride ingress after different periods of exposure to $3 \% \mathrm{NaCl}$ solution in full immersion and partial immersion modes. From the tests, it was found that the resistance to chloride penetration of concrete depends on the fineness of fly ash. The rapid chloride permeability test (ASTM C1202) decrease is promoted with an increase in fly ash fineness. The immersion of cut cylinders in the $3 \% \mathrm{NaCl}$ solution for 3 and 6 months confirm that the resistance of the chloride penetration of concrete increases with incorporation with fly ash and an increase in the fly ash fineness. From the results, It is concluded that the resistance to chloride penetration of concrete is significantly increased with the incorporation of fly ash and the increase is enhanced with an increase in fly ash fineness. The increase results from the reduced water-tobinder ratio, the reduced average pore size of the paste and the improved interfacial zone. The incorporation of fly ash is especially enhanced for the fine fly ash, due to the spherical and smooth surface of the fine fly ash particles.

The rapid chloride test clarifies the effect of fly ash and its fineness for all mixes. Both the full and the partial immersion tests of the cut specimens in the $3 \% \mathrm{NaCl}$ solution confirm the effects for the low and normal strength concretes. For the high strength concrete, the immersion tests for all mixes result in fairly low and similar penetration depth. The effects of the fly ash replacement and the fly ash fineness on the resistance to chloride penetration are highly recognized for the low and normal strength concretes.

Lee et al. (2010) examined the concrete structures immersed in seawater, the concentration of chloride used to estimate the chloride diffusion coefficient can be defined as the seawater 
chloride concentration. However, for seashore structures that are not coming into direct contact with seawater, establishing the interface concentration of chloride becomes delicate. In addition, concrete structures are greatly affected by salt attack primarily due to airborne sea salt, like it can be seen through the corrosion of rebar. This study intends to investigate salt attack by airborne sea salt in terms of the distance from the seashore through measurements conducted at 73 spots and 27 areas during 3 year in the Eastern, Western and Southern coasts of Korea. Results reveal large regional variations of salinity in coastal regions with significant seasonal effects caused by seasonal winds. Moreover, the salinity is seen to diminish as the distance from the seashore increases at a rate corresponding to the function $\mathrm{y}=\mathrm{ax}-\mathrm{b}$.

The salinity date measured during on year in 27 areas and 73 spots of the East, West and South Seas of Korea have been analyzed, Results led to the following considerations that can be exploited in estimating the distribution of seashore salinity, adjusting the revel of countermeasures against salt attack or deciding the regional order of priority.

(1) Even if seashore salinity bears specific characteristics for each coastal zone, large variations of salinity were observed in areas pertaining to the same coastal zone.

(2) The salinity developed in a sea-shore exhibiting shallow depth and complex Rias coastline or region with a large tidal range and seashore with a well developed bay is relatively small.

(3) The salinity exhibits different trends by periods and by directions in areas swept by seasonal winds or crossed by a large mountain chain. Especially, during seasons with winds blowing from the sea towards the continent, higher salinity has been observed.

(4) The salinity in terms of distance from the sea tends to reduce as the function $\mathrm{y}=\mathrm{ax}-\mathrm{b}$ as the distance increases. The salinity was also seen to reduce suddenly until a distance of 100-150 $\mathrm{m}$ from the seashore.

Concrete specimens were also subjected to outdoor exposure at seashore fields together with the measurement of

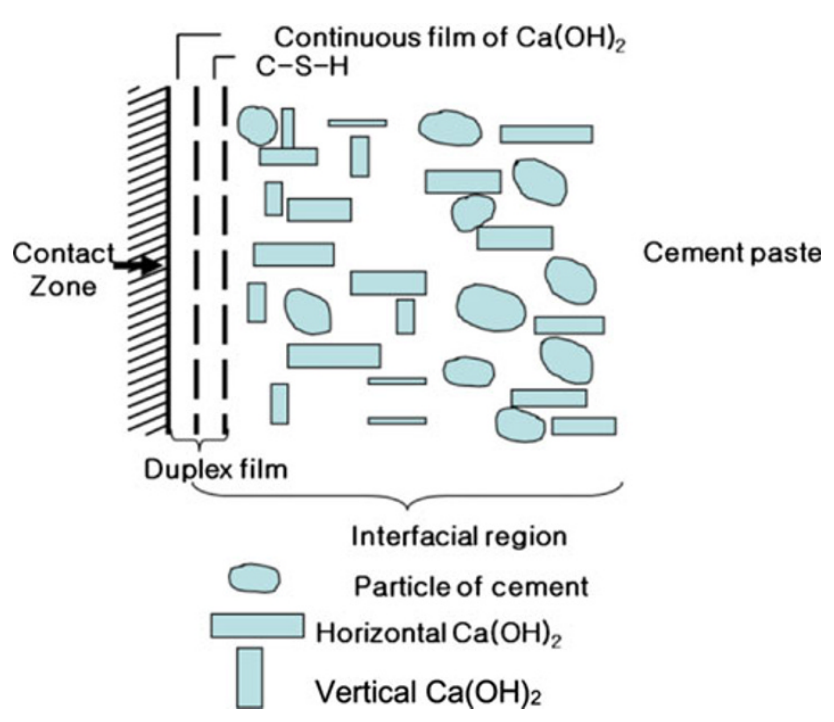

Fig. 1 Barnes model. salinity. Researches are currently carried out and will produce results investigating the diffusion of chloride in concrete structures through comparative studies on seashore salinity and salt attack in concrete.

The present study investigates the influences of formingmaterials for the chloride ion penetration of seashore concrete made by with fly-ash and silica fume.

\section{Experimental Program}

The experimental program was designed to evaluate the chloride penetration of seashore concrete cured by five different form materials using cylindrical specimen.

\subsection{Materials and Mix Proportions}

In the present work, Type 1 Portland cement produced in Korea, river sand produced in China, and crushed granite stone as coarse aggregate with a maximum size of $25 \mathrm{~mm}$ were used to make three different concrete mixes such as concrete contains $5 \%$ micro silica fume (MSF concrete), $10 \%$ fly ash (FA concrete), and no mineral contained concrete (plain concrete). The physical and chemical composition, specific gravity, fineness modulus of cement, mineral admixtures, aggregate and chemical admixture used are given in Tables 1, 2, 3 and 4, respectively. Tables 1, 2, 3 and 4 provide the manufacturer and the test results.

Three concrete types plain, MSF and FA concrete were examined. The constant water-to-cement ratio of $45 \%$ was used for all three types of concrete. The mix proportions of concrete are given in Table 5. The mixture proportions of concrete were determined to satisfy air contents of 3-6\% and target slump of $18 \pm 2.5 \mathrm{~cm}$.

In this experiment, a $50 \mathrm{~mm}$ thickness of standard specimen is cut from cylinder specimen of $100 \mathrm{~mm}$ diameter and $200 \mathrm{~mm}$ height. Other specimen samples, $50 \mathrm{~mm}$ thick, were taken from the top and bottom of the same cylinder specimen. The samples were in contact with pre-installed into the curing form films of wood, coated wood, steel and polypropylene to examine the influence of form materials into chloride penetration of seashore concrete.

\subsection{Test Procedures}

\subsubsection{Compressive Strength Test}

The compressive strengths of seashore concrete were tested at the age of 7, 28 and 90 days, using standard cylinder specimen of $100 \mathrm{~mm}$ diameter and $200 \mathrm{~mm}$ height. The test was done in accordance with the ASTM C 39 with the average of three specimens, respectively.

\subsubsection{Chloride Penetration Test}

The chloride penetration of concrete was tested with the NT build 492. The cut specimens were fully immersed in the $10 \% \mathrm{NaCl}$ solution at the age of 28 days. This test is used to simulate the fully immersed section of seashore concrete member. Other specimen samples, $50 \mathrm{~mm}$ thick, were taken from the top and bottom of the same cylinder specimen. The samples were in contact with pre-installed into the curing 
form films of wood, coated wood, steel and polypropylene to examine the influence of form materials into chloride penetration of seashore concrete. Figure 2 shows test arrangement and sliced specimen for evaluation of concrete resistance to chloride ion penetration. The chloride penetration tests were obtained after 3 months.

Table 1 Physical properties of cement.

\begin{tabular}{c|c|c|c|c|c|c|c}
\hline Specific gravity & $\begin{array}{c}\text { Blaine fineness } \\
\left(\mathrm{cm}^{2} / \mathrm{g}\right)\end{array}$ & Stability (\%) & \multicolumn{2}{|c|}{ Setting time (min) } & \multicolumn{3}{|c}{ Compressive strength (MPa) } \\
\cline { 4 - 8 } & & & Initial setting & Final setting & 3 day & 7 day & 28 day \\
\hline \hline 3.15 & 3,222 & 0.05 & 235 & 370 & 19.5 & 29.3 & 39.7 \\
\hline
\end{tabular}

Table 2 Physical and chemical composition of mineral admixtures.

\begin{tabular}{c|c|c|c|c|c|c|c|c|c}
\hline Class & \multirow{2}{*}{$\begin{array}{c}\text { Specific } \\
\text { gravity }\end{array}$} & \multirow{2}{*}{$\begin{array}{c}\text { Blaine } \\
\text { fineness } \\
\end{array}$} & & \multirow{2}{*}{ Ig. loss (\%) } & \multicolumn{5}{|c}{ Compressive strength $(\mathrm{MPa})$} \\
\cline { 5 - 10 } & & & $\mathrm{SiO}_{2}$ & $\mathrm{Al}_{2} \mathrm{O}_{3}$ & $\mathrm{Fe}_{2} \mathrm{O}_{3}$ & $\mathrm{CaO}$ & $\mathrm{MgO}$ & $\mathrm{SO}_{3}$ \\
\hline \hline MSF & 2.30 & 260,000 & 0.10 & 95.0 & 0.26 & 0.13 & 0.19 & 0.45 & 0.23 \\
\hline FA & 2.15 & 3,158 & 3.57 & 56.4 & 23.7 & 9.0 & 2.5 & 1.3 & 1.1 \\
\hline
\end{tabular}

Table 3 Physical properties of aggregates.

\begin{tabular}{c|c|c|c|c|c}
\hline Type & Specific gravity & Fineness modulus & Absorption ratio (\%) & Unit weight $\left(\mathrm{kg} / \mathrm{m}^{2}\right)$ & $\begin{array}{c}0.08 \mathrm{~mm} \text { sieve passing } \\
(\%)\end{array}$ \\
\hline \hline Fine aggregate & 2.57 & 2.7 & 1.83 & 1,470 & 1.8 \\
\hline Coarse aggregate & 2.63 & 6.9 & 0.62 & 1,577 & 0.3 \\
\hline
\end{tabular}

Table 4 Physical properties of chemical admixture.

\begin{tabular}{c|c|c|c|c}
\hline Type & Main composition & Appearance & Color & Specific gravity at $20^{\circ} \mathrm{C}$ \\
\hline \hline Superplasticizer & Naphthalene & Liquid & Dark brown & $1.20 \pm 0.02$ \\
\hline
\end{tabular}

Table 5 Mixture of concrete.

\begin{tabular}{|c|c|c|c|c|c|c|c|c|c|}
\hline \multirow[t]{2}{*}{ Type } & \multirow[t]{2}{*}{$\mathrm{W} / \mathrm{Cm}(\%)$} & \multirow[t]{2}{*}{ S/a (\%) } & \multirow[t]{2}{*}{$\mathrm{sp} / \mathrm{Cm}(\%)$} & \multirow{2}{*}{$\begin{array}{c}\text { Water content } \\
\left(\mathrm{kg} / \mathrm{m}^{3}\right)\end{array}$} & \multicolumn{5}{|c|}{ Weight mix $\left(\mathrm{kg} / \mathrm{m}^{3}\right)$} \\
\hline & & & & & Cement & Fly ash & Silica fume & Sand & Coarse agg. \\
\hline Plain & \multirow[t]{3}{*}{0.45} & \multirow[t]{3}{*}{46.7} & 0.50 & \multirow[t]{3}{*}{158} & 351 & 0 & 0 & 823 & 961 \\
\hline MSF & & & 0.95 & & 334 & 0 & 18 & 820 & 958 \\
\hline FA & & & 1.00 & & 316 & 35 & 0 & 817 & 954 \\
\hline
\end{tabular}

$W / C m$ water/cementitious materials, $S / a$ sand/aggregate, $s p / C m$ superplasticizer/cementitious materials.
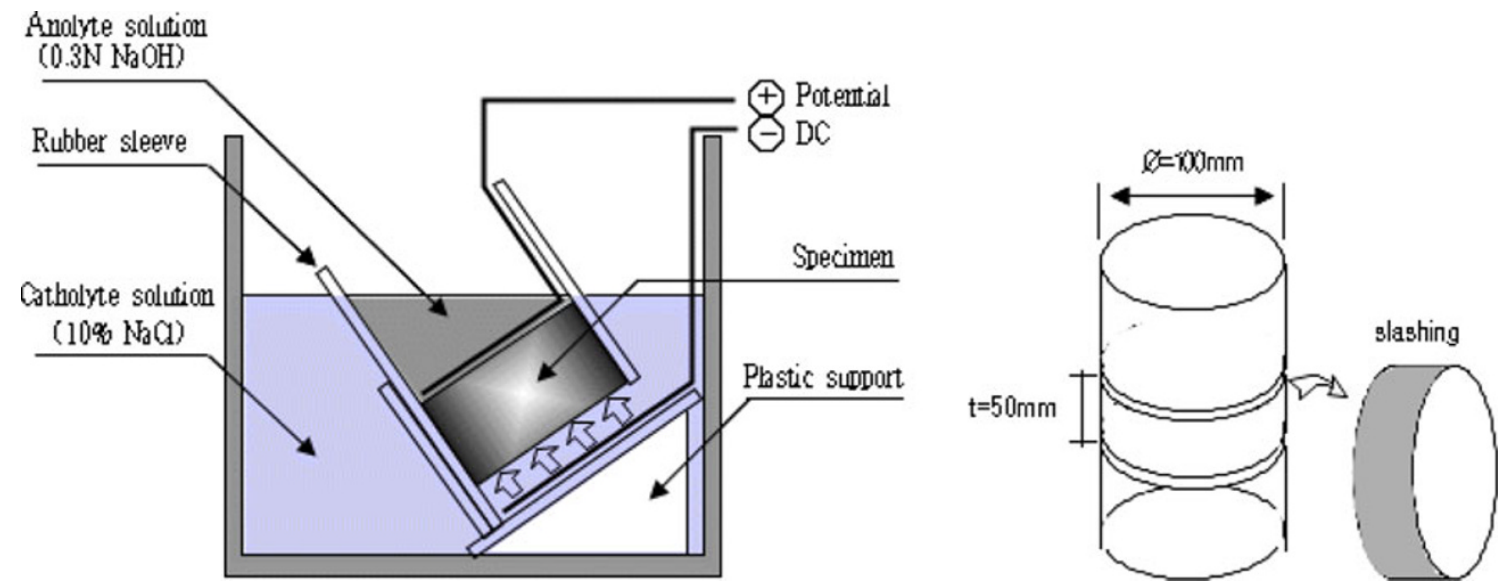

Fig. 2 Immersion of concrete specimen in $10 \% \mathrm{NaCl}$ solution. 


\subsubsection{Pore Volume Test}

The pore volume of concrete was tested with automated mercury porosimeter which determines the size and quantity of void spaces and pores in concrete. In the porosimeter, mercury is forced into pores of concrete, and fills the pores completely by the pressure. The relationship is,

$$
D=-(1 / P) 4 g^{\cos Q}
$$

where, $D$ is the pore diameter, $P$ the applied pressure, $g$ the surface tension, and $Q$ is the contact angle. The volume of mercury $V$ penetrating the pores is measured directly as a function of applied pressure. This $D-V$ information serves as a unique characterization of pore structure (Yoo et al. 2006).

\section{Results and Discussions}

\subsection{Properties of Concrete}

The average compressive strengths at the age of 7, 28, 56 and 90 days are plotted in Fig. 3. The strength development at the age of 7 days is not significantly differs with different mix components. The compressive strength of concrete contained silica-fume (MSF), however, shows higher as much as $20 \%$ compared to FA concrete and plain concrete after 28 days. Results also shows that the strength development of FA concrete until 28 days is very similar with plain concrete, but at the age of 90 days is a little higher than plain concrete. This result may be due to the pozzolan reaction of FA concrete.

\subsection{Pore Volume Tests}

The results of the pore volume tests are shown in Fig. 4 with respect to incremental pore volume and pore size diameter. The amount of total pore volume of MSF concrete is higher than other two concretes. However, plain concrete shows higher percentage of pore size greater than $1 \mu \mathrm{m}$ compare to two others. This result may be comes from the effect of micro silica-fume fillings at the pore size greater than $10 \mu \mathrm{m}$ in the MSF concrete. MSF concrete cured by steel and polypropylene materials shows much higher pore volume amount than plain and FA concretes for the pore size

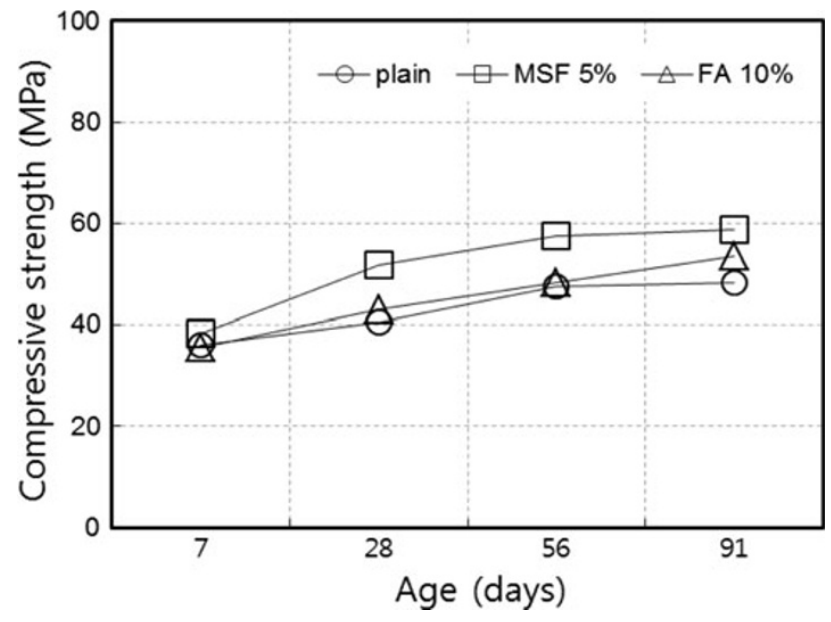

Fig. 3 Test result of compressive strength. between 0.1 and $1.0 \mu \mathrm{m}$. This result may be due to the effect of silica-fume fillings between pores.

\subsection{Ingress Time}

The results of the chloride migration tests are shown in Fig. 5 with respect to the different curing form materials. The chloride migration coefficient was calculated using Eq. (1) which taken from the Ref. (Rukzon and Prinya 2011).

$$
D_{\text {nssn }}=\frac{0.0239(273+T) L}{(U-2) t}\left\{X_{\mathrm{d}}-0.0238 \sqrt{\frac{(273+T) L X_{d}}{U-2}}\right\}
$$

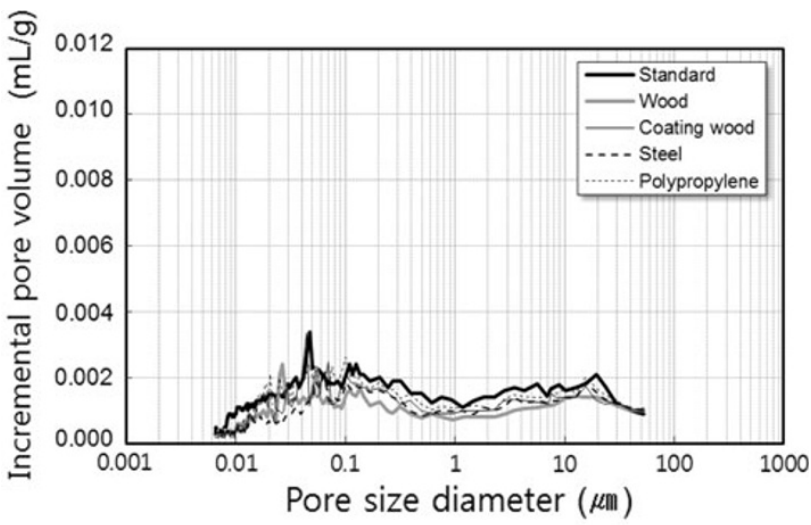

(a) plain concrete

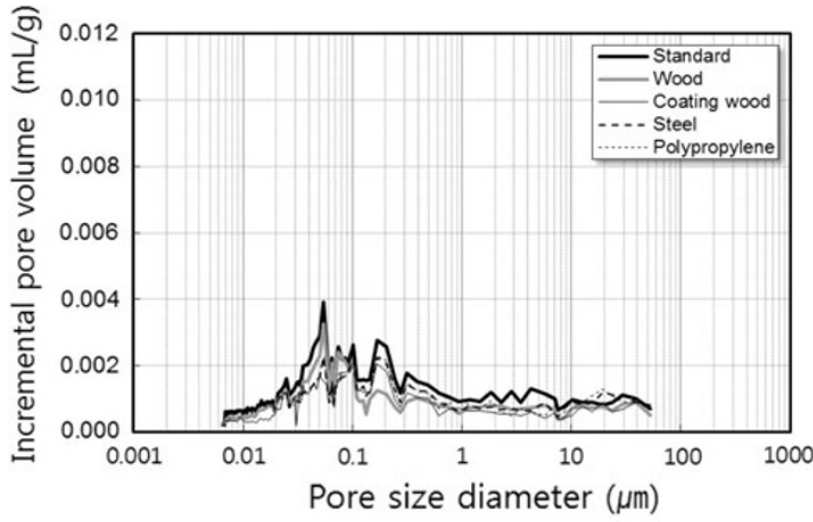

(b) FA concrete

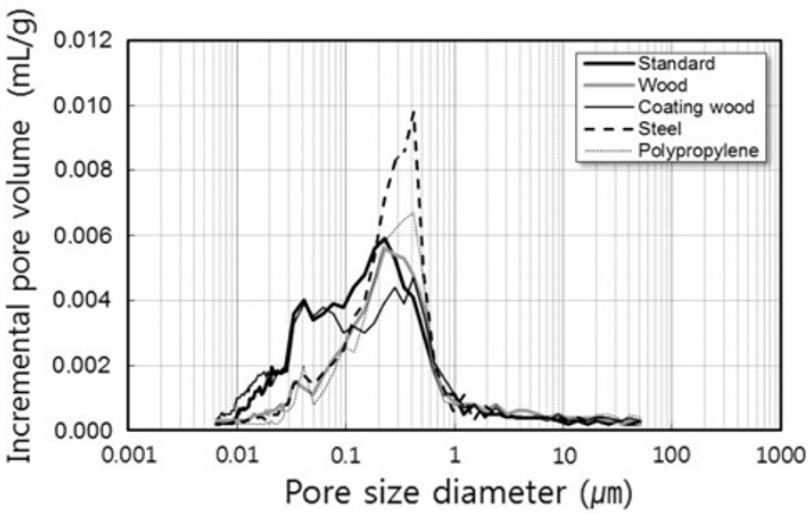

(c) MSF concrete

Fig. 4 Properties of pore volume by mineral admixture and form facing materials a plain concrete b FA concrete c MSF concrete. 
where $D_{\text {nssrn }}$ is the non-steady-migration coefficient $\left(\times 10^{-12}\right.$ $\left.\mathrm{m}^{2} / \mathrm{s}\right), U$ the absolute value of the applied voltage $(\mathrm{V}), T$ the average value of initial and final temperatures in the anolyte solution $\left({ }^{\circ} \mathrm{C}\right), L$ the thickness of the specimen $(\mathrm{mm}), X_{\mathrm{d}}$ the average value of the penetration depths $(\mathrm{mm}), t$ is the test duration (h).

The average chloride migration coefficient of plain concrete ranged 19.3-21.1 $\times 10^{-12}\left(\mathrm{~m}^{2} / \mathrm{s}\right)$, MSF concrete does $12.3-14.2 \times 10^{-12}\left(\mathrm{~m}^{2} / \mathrm{s}\right)$ and FA concrete does 17.5$19.8 \times 10^{-12}\left(\mathrm{~m}^{2} / \mathrm{s}\right)$.

In order to identify the effect of the curing form materials, the chloride migration coefficients were compared for five different form materials including standard form material from Fig. 5. The plain concrete shows that the wood form material has the greatest resistance to chloride penetration compared to four other materials with maximum different of $13 \%$ approximately. MSF concrete shows that the polypropylene film form material has the greatest resistance to chloride penetration compared to four other materials with maximum different of $15 \%$ approximately. FA concrete shows that the coating wood form material has the greatest resistance to chloride penetration compared to four other materials.

Table 6 shows the calculation of chloride ingress time using Eq. (2) for concrete types and form materials. To calculate ingress time, $\beta_{\mathrm{t}}=3.72$ was adopted in Eq. (2) because that this value means the probability of failure is $10 \%$ before failed its estimated concrete life, and other values needed in calculation are taken from Duracrete Final Technical Report (Project BE95-1347) (Duracrete 2000).

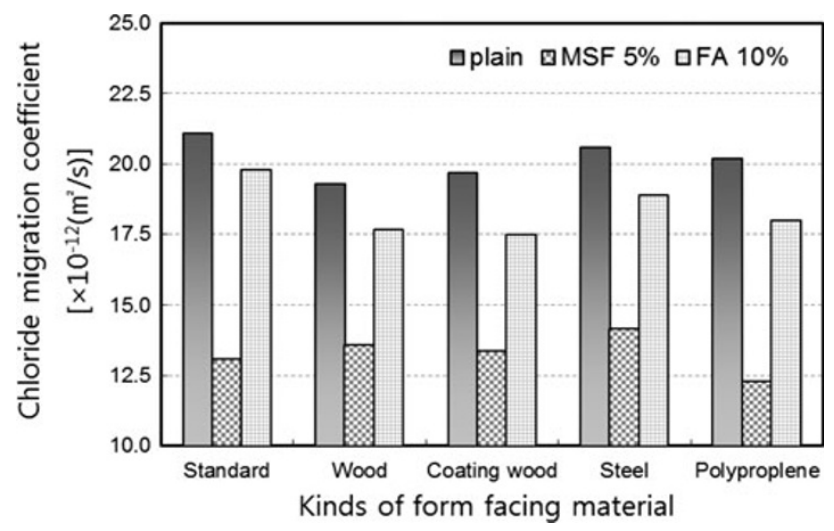

Fig. 5 Properties of chloride migration by kinds of facing materials.

$$
\begin{gathered}
t_{i}^{d}=\left[\left\{\frac{2}{x^{c}-\Delta x} \cdot e^{-1}\left(1-\frac{c_{c r}^{c}}{\gamma_{c_{c r}}} \cdot \frac{1}{A_{c_{s, c l}} \cdot \frac{\omega}{c m} \cdot \gamma_{c_{s, c l}}}\right)\right\}^{-2}\right. \\
\left.\cdot \frac{R_{o, c l}^{c}}{k_{e, c l}^{c} \cdot k_{c, c l}^{c} \cdot t_{o}^{c} \cdot \gamma_{R c l}}\right]^{\frac{1}{1-n_{c l}^{c}}}
\end{gathered}
$$

where $x^{c}$ is the characteristic value of the concrete cover $(\mathrm{mm}), \Delta x$ the margin for the concrete cover $(\mathrm{mm}), c_{c r}^{c}$ the characteristic value of the critical concentration $(\%), \gamma_{c_{c r}}$ the partial factor for the critical chloride concentration, $A_{c_{s, c l}}$ the characteristic value of the regression parameter describing the relation between the chloride surface concentration and the water-binding ratio $(\%), \omega / \mathrm{cm}$ the water/cementious materials ratio, $\gamma_{c_{s c l}}$ the partial factor for the surface chloride connection, $k_{e, c l}^{c}$ the characteristic value of the environment factor, $k_{c, c l}^{c}$ the characteristic value of the curing factor, $t_{\mathrm{o}}$ the age of the concrete when the compliance test is performed (corresponding to 28 days), $n_{c l}^{c}$ the characteristic value of the age factor, $\gamma_{R c l}$ the partial factor of the resistance, $R_{o, c l}^{c}$ the characteristic value of the resistance (year $/ \mathrm{mm}^{2}$ ) (corresponding to chloride migration coefficient, $\times 10^{-12} \mathrm{~m}^{2} / \mathrm{s}$ )

It could be found that chloride ingress time was very different depending on the concrete surface finishing even within the same concrete. The difference of chloride ingress time in plain concrete, MSF concrete and FA concrete were evaluated by $115.2,125.5$ and $121.6 \%$, respectively.

\section{Conclusions}

To investigate the effect of concrete surface finishing on the chloride ingress for marine structures, compressive strength, chloride migration and pore structure of concrete with various finishing methods were evaluated and then chloride ingress time was calculated based on test results. The results of this study can be summarized as follows.

1. The effect of different cementitious materials on compressive strength of concrete was marginal at the age of 7 days. However, at the age of 28 days the compressive strength of MSF concrete was higher than those of plane concrete and FA concrete by 21.6 and $17.2 \%$, respectively.

2. Concrete using standard form had more pores than concrete using forms made of steel or polypropylene film. Concrete using wood form had the least pores.

\begin{tabular}{|c|c|c|c|c|c|c|c|c|c|c|c|c|c|c|c|}
\hline & \multicolumn{5}{|c|}{ Plain concrete $(\max 115.1 \%)$} & \multicolumn{5}{|c|}{ MSF concrete $(\max 125.5 \%)$} & \multicolumn{5}{|c|}{ FA concrete $(\max 121.6 \%)$} \\
\hline & Standard & Steel & Wood & $\begin{array}{c}\text { Coating } \\
\text { wood } \\
\end{array}$ & \begin{tabular}{|c|}
$\begin{array}{c}\text { Poly- } \\
\text { propylene }\end{array}$ \\
\end{tabular} & Standard & Steel & Wood & $\begin{array}{c}\text { Coating } \\
\text { wood }\end{array}$ & \begin{tabular}{|c|}
$\begin{array}{c}\text { Poly- } \\
\text { propylene }\end{array}$ \\
\end{tabular} & Standard & Steel & Wood & \begin{tabular}{|c|}
$\begin{array}{c}\text { Coating } \\
\text { wood }\end{array}$ \\
\end{tabular} & $\begin{array}{c}\text { Poly- } \\
\text { propylene }\end{array}$ \\
\hline$A_{c_{s, c l}}$ & \multicolumn{5}{|c|}{$7.76 \%$} & \multicolumn{5}{|c|}{$8.96 \%$} & \multicolumn{5}{|c|}{$7.46 \%$} \\
\hline$\overline{D_{0, c l}^{c}}$ & 21.1 & 20.6 & 19.3 & 19.7 & 20.2 & 13.1 & 14.2 & 13.6 & 13.4 & 12.3 & 19.8 & 18.9 & 17.7 & 17.5 & 18.0 \\
\hline$R_{0, c l}^{c}$ & 0.001502 & 0.001539 & 0.001643 & 0.001609 & 0.001569 & 0.002420 & 0.002233 & 0.002331 & 0.002366 & 0.002578 & 0.001601 & 0.001677 & 0.001791 & 0.001812 & 0.001761 \\
\hline$t_{i}^{d}$ & 21.1 & 22.0 & 24.3 & 23.6 & 22.6 & 40.5 & 35.7 & 38.2 & 39.1 & 44.8 & 24.1 & 26.0 & 28.8 & 29.3 & 28.1 \\
\hline
\end{tabular}

Table 6 Values of the factor (Yoo et al. 2006; Edvardsen et al. 2006).

$x^{c} 100 \mathrm{~mm}, \Delta x 20 \mathrm{~mm}, c_{c r}^{c} 0.675 \%, \gamma_{c r} 1.20, w / b 0.45, \gamma_{c_{s, c l}} 1.60, k_{e, c l}^{c} 0.79, t_{0} 0.0767, \gamma R c l 3.25$. 
MSF concrete had much more pores of $0.1-1 \mu \mathrm{m}$ sizes than plain concrete and FA concrete.

3. It could be found that chloride ingress time was very different depending on the concrete surface finishing even within the same concrete. The difference of chloride ingress time in plain concrete, MSF concrete and FA concrete were evaluated by $115.2,125.5$ and $121.6 \%$, respectively.

4. In durability design for Duracrete, various property items are applies to evaluate the service life of concrete based on the probabilistic reliability theory. If various concrete surface finishing is added in durability design for Duracrete as a evaluation item, the reliability of durability design might be better.

\section{Open Access}

This article is distributed under the terms of the Creative Commons Attribution License which permits any use, distribution, and reproduction in any medium, provided the original author(s) and the source are credited.

\section{References}

Barnes, B. D., Diamond, S., \& Dolch, W. L. (1978). The contact zone between Portland cement paste and glass "aggregate" surface. Cement and Concrete Research Journal, 8(2), 233-244.

Duracrete (2000). Probabilistic performance based durability design of concrete structures, Document BE95-1347/R17. Final Technical Report. The Netherlands, CUR, European Brite-EuRam Programme.

Edvardsen, C. K., Kim, Y. J., Park, S. J., Jeong, S. K., \& Im, H. C. (2006). Busan-Geoje fixed link concrete durability design for the bridges and tunnels, ITA WTC.

Lee, J. S., Ahn, K. H., Kim, D. G., \& Park, J. J. (2010). Distribution properties of airborne chlorides in Korea. Journal of the Korea Concrete Institute, 22(6), 769-776 (in Korean).

Nordtest Method NT Build 492 (1999): Concrete, Mortar and cement-based repair materials, choride migration coefficient from non-steady migration experiments.

Rukzon, S., \& Chindaprasirt, P. (2011). Chloride penetration and corrosion resistance of ground fly ash blended cement mortar. International Journal of Materials Research, 102(3), 335-339.

Yoo, J. K., Park, S. J., Oh, B., \& Kim, S. W. (2006). An experimental study on the finish-ability improvement of high performance marine concrete. The 2nd Asian Concrete Federation Conference, Bali, Indonesia. 